\title{
RISING FIGURES IN STUDENT DEPRESSION: CAN EXERCISE REPLACE PHARMACEUTICALS? \\ Nicola McQuillan
}

\section{INTRODUCTION}

The increase in mental illness in New Zealand is undisputed and currently there is a lot of work being done to promote mental health awareness and create a society free of discrimination (Ministry of Health, 2019). What perhaps is not so widely recognised is the extent of depression and anxiety within our tertiary student community. Many students will make the transition from secondary school to a tertiary education environment with little or no problem, but others, particularly those with pre-existing mental health issues, will struggle. Factors such as Ioneliness, relationship issues, financial difficulty, homesickness, fear of failure, and juggling work commitments with study commitments are believed to be contributors. It may well be due to the fact stigma associated with mental health struggles is diminishing that we are seeing an increase in young people seeking help. This is both encouraging and concerning. Students aged between 18 and 25 years old are more likely to experience adverse effects of stress and have the highest rate of depression and suicide compared to any other group (NZ Mortality Review Data Group, 2013; Sarokhani et al., 2013). Antidepressant medication is widely available and easily obtained. However, this treatment does not come without obstacles. In some patients, it may take many months of trial and error to determine the most effective medication and dosage. A lack of patient education and follow-up care is a lead reason for non-adherence to medication and resulting in lack of trust in healthcare system (Unützer \& Park, 20I2).

Due to the disproportionate rate of depression and suicide among young New Zealanders between 18- and 25 -year-olds, this paper is primarily focusing on these individuals within a tertiary education environment (New Zealand Union of Students' Associations, 2018). By reviewing literature and scientific findings regarding exercise as a management option for depression, this paper makes a comparison between traditional pharmaceutical therapy, and what improvements can be made from a nursing perspective.

\section{PHARMACUTICAL TREATMENT}

Antidepressants are a medication used to manage moods, anxiety, social functioning, energy levels and sleep. In New Zealand, prescriptions of antidepressants rose by 21 percent between 2008 and 2015. By these statistics, one in eight adults in New Zealand have been prescribed this medication as at 2018 (Aselton, 20I0; Russell, 20I8). Some common side effects of these medications include nausea, headaches, strange dreams, difficulty sleeping, sexual dysfunction and for the first couple weeks of taking antidepressants, increased suicidal ideation is common (Santarsieri \& Schwartz, 2015).

While there is little evidence and research surrounding the link between antidepressants and suicidal ideation, it is generally accepted that antidepressants can cause violent behavior and suicidal ideation in children and adolescents. However, one study comparing antidepressants to placebo in healthy adults with no sign of mental disorder found suicidal ideation to be a prominent side effect in the antidepressant group (Andalo, 2016). While Stübner et al, (2018) suggests that suicidal ideation is a rare side effect of antidepressants, Andalo (2016) conversely advocates that it is vastly underestimated. 
Selective serotonin reuptake inhibitors (SSRIs) are often the preferred variety of antidepressants to prescribe as they tend to have milder side effects and are often more effective for patients (Ferguson, 200I). However, SSRIs are not a "one size fits all" solution for depression as the effects of the drug vary for individuals. It is assumed that approximately 50 percent of patients have a positive outcome with antidepressant treatment including a decrease in symptoms, whereas others have a negative or "mixed" experience and require further trials with other types of drugs within the class, or alternative treatments (Gibson, Cartwright, \& Read, 2016).

Non-adherence to pharmaceutical treatments is a common occurrence within mental illness for a variety of reasons. A 2017 study conducted by Ho, Jacob, and Tangiisuran found that some of the barriers that caused nonadherence with antidepressant drug therapy were lack of understanding of depression as an illness, as well as a lack of education surrounding the drug itself. While some believed that because they were lacking symptoms on a particular day, it wasn't necessary to continue to take medication, others found the side effects undesirable. For some, cultural or personal beliefs surrounding antidepressants cause suspicion whether the pharmaceutical companies are more interested in making money than they are about personal health, or that by swallowing a tablet each day they are being 'lazy' for taking the easy option, as opposed to 'working through' the underlying issues and root cause. Furthermore, this study found that perceived health benefits facilitated adherence as well as positive effects of medication as opposed to patients who had negative beliefs towards antidepressants.

Among university students specifically, evidence suggests that lack of adherence to antidepressant medication regime is due to forgetting, fearing dependency, not finding the medication effective, or a desire to find alternative solutions as opposed to pharmaceutical treatment (Hammonds et al., 2015).

Cartwright, Gibson, Read, Cowan, and Dehar conducted a study in 2016 in New Zealand examining patients' views of long-term (between 3 and 15 years) antidepressant treatment and the adverse side effects of these. The results of this study showed that while these treatments were effective in reducing depressive symptoms for almost 90 percent of participants, many had concerns regarding the side effects. Of these, the most commonly reported were weight gain (65.3 percent), emotional numbness or apathy (64.5 percent), sexual dysfunction/effect on libido (7l.8 percent), as well as withdrawal symptoms ( 73.5 percent) and addiction to treatment (43 percent).

\section{EXERCISE}

It has long been an accepted fact that exercise is an effective treatment in a variety of illnesses and disabilities, including mental health. Though the antidepressant factor of exercise isn't clear, it is thought that it is related to sleep regulation, and the physiological and hormonal response to exercise that reduces depressive symptoms as well as reducing side effects of antidepressant medication (Jorm et al., 2006). Aselton (2010) compared a number of studies, one of the main findings throughout this literature was that many students found exercise was an effective coping strategy, one participant even citing exercise as "life-saving." This study found commonality among these students, who found that exercise lifted mood and helped them to deal with stress appropriately, an expected finding according to a review of related literature (Aselton, 20 I0; Jorm et al., 2006). A study conducted with groups of participants that had either a mood disorder diagnosis or non-clinical depression, both groups were found to have had a positive effect on mood and a significant decline in depressive symptoms compared to the control groups (Stathopoulou, Powers, Berry, Smits, \& Otto, 2006). There is, however, limited research regarding the effects of exercise on depression compared with the effects of antidepressants as exercise is often treated as complementary to antidepressants as opposed to stand-alone treatment. One study found that there was little to no significant difference between exercise as treatment and pharmaceutical therapy, therefore concluding that exercise is a comparable treatment to antidepressants and psychotherapy. This study also indicates that in the treatment of depression, exercise works best in conjunction with an effective antidepressant medication regime (Aselton, 2010; Kvam, Kleppe, Nordhus, \& Hovland, 2016). 
Though there is no advisable "dose" of exercise that patients with depression should commit to, it is essential that patients maintain regular exercise and consider it as a longer-term treatment for depression. This topic would also benefit from further research regarding the benefits of exercise in depression treatment as it would observe adherence issues, as well as professional and economic matters. This would require a longitudinal observational study where subjects are able to be studied and monitored over a period of time (Aselton, 20 I0; Blumenthal, Smith, \& Hoffman, 2012; Caruana, Roman, Hernández-Sánchez, \& Solli, 2015). Regarding students specifically, Aselton (2010) also found that participants with social support were more likely to engage in healthy habits such as exercise or expressing their emotions to their friends, perhaps suggesting a need that could be met through tertiary organisations.

\section{PHYSIOLOGICIAL FACTORS}

Though the definitive reason why exercise has a positive effect of mood is undetermined, Netz (2017) found that exercise potentially facilitates brain derived neurotrophic factor (BDNF) as a mechanism that lowers depression. BDNF is often found to be in lower concentrations in depressed individuals, and upon treatment of antidepressants for at least four weeks, BDNF is replenished back to normal levels (Lee \& Kim, 20I0). Involved in activity-dependent neuronal plasticity, such as memory and learning, a decline of BDNF does not necessarily cause depression, but appears to have some link. Evidence from clinical studies does show that when a patient has major depression, their brain suffers from a neuronal dysfunction or decreased occurrence in BDNF activity (Lee \& Kim, 2010).

Several studies show that exercise likely activates molecular mechanisms in the neuromuscular system, triggering an increase in BDNF. However, it is more likely that the antidepressant effect of exercise is not solely from BDNF, but several neurobiological mechanisms (Gómez-Pinilla, Ying, Roy, Molteni, \& Edgerton, 2002). These effects, especially when in combination with pharmaceutical therapies, can have a response as early as within two days, as opposed to antidepressants alone requiring at least four weeks to take effect (Kvam et al., 2016; Netz, 20 I7).

\section{RECOMMENDATIONS}

\section{Early Intervention}

The best option for treating depression is early intervention and prevention where possible. For university students, many may not have been professionally diagnosed with depression. If these students can be identified, provided appropriate health services and treated for depression, it would decrease risk of suicide or other consequences of depression (Phimarn, Kaewphila, Suttajit, \& Saramunee, 20I5). Tertiary education institutes and their staff have a responsibility to support students struggling with mental illness and should be vigilant in identifying individuals that require this extra support, particularly due to the fact that grades and academic pressure is a prominent cause for stress and depression among students (Kang et al., 2013). Studies show that individuals are more likely to be treated for depression in a primary healthcare setting rather than by a mental health professional, however, these primary health professionals fail to recognize and treat depression in 30 to 50 percent of these patients. These statistics give little hope for sufferers of depression, and screening tools should be proficiently exercised in an attempt at early intervention (Pignone et al., 2002).

As for the role of academic staff, specific training could be provided regarding depression in students to enhance counselling abilities and strategies which promote awareness and provide students with a sense that they are supported emotionally and academically while they study (Phimarn et al., 2015). 


\section{Encouraging exercise}

There is promising evidence that many self-help interventions, including exercise, reduce depressive symptoms (Morgan \& Jorm, 2008). As discussed previously, evidence suggests that exercise is just as effective at treating depression as pharmaceutical therapies and is even more effective when used in conjunction with antidepressants (Netz, 2017). An appropriate recommendation for students with depression or someone caring for a depressed individual is to encourage regular exercise by incorporating it into daily routine. For tertiary institutes, offering free group exercise classes may be effective. One study showed that when free exercise classes were available in a neighbourhood park, physical activity of park users increased by two to three times (Han et al., 2015). This could be applied to students by offering more free exercise groups, classes and clubs to encourage a similar result. As Aselton (2010) suggested, organised groups are more likely to engage in healthier habits. Tertiary organisations can encourage or even enforce support groups that perhaps study or exercise together. Tertiary organisations could use these groups to have fortnightly or monthly group projects worth a small percentage of class grades. This could make a huge difference in someone's social situation and mental health, as well as relieve academic stress.

\section{Education surrounding mental illness and SSRIs}

Left untreated, patients with depression have a lower quality of life, are more likely to commit suicide, and experience worse outcomes for physical co-morbidities (Williams, Chung, \& Muennig, 2017). Antidepressants (including SSRIs) can be particularly effective in treating depression under the right circumstances. As with all medication, there are factors that must be considered for use in every patient, such as the side effect profile, ease of use, and interactions with other medication (Simon, 2019). Barriers for antidepressant medication adherence include lack of education surrounding mental illness, side effects, and social stigma about antidepressants (Ho et al., 2017). The way we can target these barriers is by educating patients, their families, as well as the general population about antidepressants and how they work. The New Zealand Government has made considerable improvements in the budget for mental health and well-being, prioritising mental health with a focus on this along with well-being and addiction initiatives in the 2019 Budget (Ministry of Health, 2019). However, it is the role of health professionals to be educated around mental illness, treatment, and raise awareness in every area of healthcare as to dissolve the stigma and discussion about mental health.

\section{Nursing Perspective}

Serving as advocates for the best health outcome for patients through education and knowledge sharing is a fundamental part of the nurse's role, and indeed is one of the most valuable services a nurse can provide. As nurses are considered a trustworthy resource, it is an excellent position to teach students about depression, how to recognise it among their peers, about antidepressant treatments, as well as alternative methods of dealing with stress and depressive symptoms (Aselton, 2010). Within institutes and community settings, nurses play a pivotal role in the treatment of depression. Along with providing a range of therapeutic interventions, there is an opportunity for health care professionals to present current best practice information, guidance regarding compliance, and offer reassuring comfort. This allows the patient to make informed decisions regarding their own well-being, as well as strengthening the patient's trust and confidence, leading to improved health outcomes. 


\section{CONCLUSION}

With the highest rates of depression and suicide in the country, the need for the provision for improved services and support for tertiary students should be a priority consideration for all healthcare and education personnel, from triage nurses to policy makers (Aselton, 2010; NZ Mortality Review Data Group, 2013).

Though antidepressants often provide an improvement in depressive symptoms, this is not the only form of treatment available. Exercise is proven to be just as effective alone and improves results when combined with antidepressants (Netz, 2017). Exercise is not constrained by cultural, social, or economic backgrounds, is inexpensive, and can be worked into any schedule. Exercise is a powerful holistic treatment that is deserving of inclusion in all mental health intervention (Aselton, 2010). All education providers have a responsibility to their students to have a level of awareness around mental health; this could facilitate early intervention for students who may otherwise not seek support of their own volition.

Nicola McQuillan is a young woman entering the nursing profession with her Bachelor of Nursing in 2020. She has a passion for mental health advocacy stemming from her experience working as a mental health support worker alongside her degree. Nicola hopes to see a raised awareness of all mental illness and treatment options for New Zealand's future.

Correspondence to: Nicola McQuillan, School of Nursing, Otago Polytechnic | Te Kura Matatini ki Otago, Forth Street, Private Bag 1910, Dunedin 9054, New Zealand. Email: Nicola.mcquillan@hotmail.com

\section{REFERENCES}

Andalo, D. (2016) Antidepressants associated with increased risk of suicidal thoughts in healthy adults. The Pharmaceutical Journal. Retrieved from https://www.pharmaceutical-journal.com/news-and-analysis/news/antidepressants-associatedwith-increased-risk-of-suicidal-thoughts-in-healthy-adults/20201834.article?firstPass=false

Aselton, P. J. (2010). The lived experience of college students who have been medicated with antidepressants. Open Access Dissertations. 235. https://scholarworks.umass.edu/open_access_dissertations/235

Blumenthal, J. A., Smith, P. J., \& Hoffman, B. M. (2012). Is exercise a viable treatment for depression? ACSM's Health \& Fitness Journal, I6(4), I4-21. https://doi.org/I0.1249/0I.FIT.00004I6000.09526.eb

Cartwright, C., Gibson, K., Read, J., Cowan, O., \& Dehar, T. (2016). Long-term antidepressant use: Patient perspectives of benefits and adverse effects. Patient Preference and Adherence, 10, 140I-1407. https://doi.org/I0.2147/PPA.SII0632

Caruana, E. J., Roman, M., Hernández-Sánchez, J., \& Solli, P. (20I5). Longitudinal studies. Journal of Thoracic Disease, 7(II), E537-E540. https://doi.org/l0.3978/j.issn.2072-1439.2015.10.63

Ferguson, J. M. (200I). SSRI Antidepressant medications: Adverse effects and tolerability. Primary Care Companion to the Journal of Clinical Psychiatry, 3(I), 22-27. https://doi.org/I0.4088/pcc.v03n0I05

Gibson, K., Cartwright, C., \& Read, J. (2016). 'In my life antidepressants have been...': a qualitative analysis of users' diverse experiences with antidepressants. BMC psychiatry, 16, 135. https://doi.org/l0.1/86/s/2888-016-0844-3

Gómez-Pinilla, F., Ying, Z., Roy, R. R., Molteni, R., \& Edgerton, V. R. (2002). Voluntary exercise induces a BDNF-mediated mechanism that promotes neuroplasticity. Journal of Neurophysiology, 88(5), 2187-2195. https://doi.org/I0.1/152/jn.00152.2002 
Hammonds, T., Rickert, K., Goldstein, C., Gathright, E., Gilmore, S., Derflinger, B., ... Hughes, J. W. (20I5). Adherence to antidepressant medications: A randomized controlled trial of medication reminding in college students. Journal of American College Health, 63(3), 204-208. https://doi.org/10.1080/07448481.2014.975716

Han, B., Cohen, D. A., Derose, K. P., Marsh, T., Williamson, S., \& Loy, S. (2015). Effectiveness of a free exercise program in a neighborhood park. Preventive Medicine Reports, 2, 255-258. https://doi.org/l0.1016/j.pmedr.2015.03.010

Ho, S. C., Jacob, S. A., \& Tangiisuran, B. (2017). Barriers and facilitators of adherence to antidepressants among outpatients with major depressive disorder: A qualitative study. PloS ONE, 12(6), e0179290. https://doi.org//0.137//journal.pone.0179290

Jorm, A. F., Allen, N. B., O'Donnell, C. P., Parslow, R. A, Purcell, R. \& Morgan, A. J. (2006). Effectiveness of complementary and self-help treatments for depression in children and adolescents. Medical Journal of Australia, 185(7), 368-372.

Kang, J., Ko, Y. K., Lee, H. K., Kang, K. H., Hur, Y., Lee, K. H. (20I3). Effects of self-esteem and academic stress on depression in Korean students in health care professions. Journal of Korean Academy of Psychiatric and Mental Health Nursing, 22(I), 56-64.

Kvam, S., Kleppe, C. L., Nordhus, I. H., \& Hovland, A. (2016). Exercise as a treatment for depression: A meta-analysis. Journal of Affective Disorders, 202, 67-86. https://doi.org/I0.1016/j.jad.2016.03.063

Lee, B. H., \& Kim, Y. K. (2010). The roles of BDNF in the pathophysiology of major depression and in antidepressant treatment. Psychiatry Investigation, 7(4), 231-235. https://doi.org/l0.4306/pi.2010.7.4.231

Ministry of Health. (2019). Mental health. Retrieved from https://www.health.govt.nz/our-work/mental-health-and-addictions/ mental-health

Morgan, A. J., \& Jorm, A. F. (2008). Self-help interventions for depressive disorders and depressive symptoms: a systematic review. Annals of General Psychiatry, 7, 13. https://doi.org/I0.1186/I744-859X-7-13

New Zealand Union of Students' Associations. (2018). Kei Te Pai? Report of student mental health in Aotearoa. Wellington, New Zealand: Author. Retrieved from https://gallery.mailchimp.com/bl09fde7924adea2d9afaa28d/files/3d3cdb2b-c0ef-4l9I847e-3f32b0bf2leb/Kei_Te_Pai_Report_on_Student_Mental_Health.pdf

Netz, Y. (2017). Is the comparison between exercise and pharmacologic treatment of depression in the clinical practice guideline of the American college of physicians evidence-based? Frontiers in Pharmacology, 8, 257. https://doi.org/l0.3389/fphar.2017.00257

NZ Mortality Review Data Group. (2013). NZ child and youth mortality review committee 9th data report: 2008-2012. Retrieved from https://www.hqsc.govt.nz/assets/CYMRC/Publications/CYMRC-ninth-data-report-2008-20I2.pdf

Pignone, M., Gaines, B. N., Rushton, J. L., Mulrow, C. D., Orleans, C. T., Whitener, B. L., ... Lohr, K. N. (2002). Screening for depression systematic evidence review. Research Triangle Institute - University of North Carolina, Evidence-based Practice Center. Retrieved from https://www.ahrq.gov/downloads/pub/prevent/pdfser/depser.pdf

Phimarn, W., Kaewphila, P., Suttajit, S., \& Saramunee, K. (2015). Depression screening and advisory service provided by community pharmacist for depressive students in university. SpringerPlus, 4, 470. https://doi.org/l0.1I86/s40064-015-1259-1

Russell, E. (2018, 9 November). One in eight Kiwi adults prescribed antidepressants. New Zealand Herald. Retrieved from https:// www.nzherald.co.nz/nz/news/article.cfm?c_id=|\&objectid=12156858

Santarsieri, D., \& Schwartz, T. L. (2015). Antidepressant efficacy and side-effect burden: A quick guide for clinicians. Drugs in context, 4. https://doi.org/10.7573/dic.212290

Sarokhani, D., Delpisheh, A., Veisani, Y., Sarokhani, M. T., Manesh, R. E., \& Sayehmiri, K. (20I3). Prevalence of depression among university students: A systematic review and meta-analysis study. Depression Research and Treatment, 2013, I-7. https://doi. org/10.1155/2013/373857

Simon, G. (2019). Patient education: Depression treatment options for adults (Beyond the Basics). UpToDate. Retrieved from https://www.uptodate.com/contents/depression-treatment-options-for-adults-beyond-the-basics\#HI

Stathopoulou, G., Powers, M. B., Berry, A. C., Smits, J. A. J., \& Otto, M. W. (2006). Exercise interventions for mental health: A quantitative and qualitative review. Clinical Psychology: Science and Practice, 13(2), 179-193. https://doi.org//0.1III/j.14682850.2006.00021.x

Stübner, S., Grohmann, R., Greil, W., Zhang, X., Müller-Oerlinghausen, B., Bleich, S., ... Neyazi, A. (20l8). Suicidal ideation and suicidal behavior as rare adverse events of antidepressant medication: Current report from the AMSP multicenter drug safety surveillance project. The International Journal of Neuropsychopharmacology, 2I(9), 814-82I. https://doi.org/I0.I093/ ijnp/pyy048

Unützer, J., \& Park, M. (2012). Strategies to improve the management of depression in primary care. Primary Care: Clinics in Office Practice, 39(2), 415-431. https://doi.org/10.1016/j.pop.2012.03.010

Williams, S. Z., Chung, G. S., \& Muennig, P. A. (2017). Undiagnosed depression: A community diagnosis. SSM - Population Health, 3, 633-638. https://doi.org/10.1016/j.ssmph.2017.07.012 